Article

\title{
Evaluation of Freeze-Thaw Erosion in Tibet Based on Cloud Model
}

\author{
Taoying Hu ${ }^{1}$, Junfu Fan 1,", Xiao Yu ${ }^{1}$, Yuke Zhou ${ }^{2}$, Peng Zhang ${ }^{1}$ and Liusheng Han ${ }^{1}$ \\ 1 School of Civil and Architectural Engineering, Shandong University of Technology, Zibo 255000, China; \\ huty_sdut@163.com (T.H.); fanjf@sdut.edu.cn (J.F.); yux_sdut@163.com (X.Y.); zhangp_sdut@163.com (P.Z.); \\ hanls@sdut.edu.cn (L.H.) \\ 2 Ecology Observing Network and Modeling Laboratory, Institute of Geographic Sciences and Natural \\ Resources Research, Chinese Academy of Sciences, Beijing 100101, China; zyk@lreis.ac.cn (Y.Z) \\ * Correspondence: fanjf@sdut.edu.cn; Tel.: +86-153-0533-0963 (J.F.)
}

\begin{abstract}
Traditionally, studies on freeze-thaw erosion have used the analytic hierarchy process (AHP) to calculate the weight of evaluation factors, however, this method cannot accurately depict the fuzziness and randomness of the problem. To overcome this disadvantage, the present study has proposed an improved AHP method based on the cloud model to evaluate the impact factors in freeze-thaw erosion. To establish an improved evaluation method for freeze-thaw erosion in Tibet, the following six factors were selected: annual temperature range, average annual precipitation, slope, aspect, vegetation coverage, and topographic relief. The traditional AHP and the cloud model were combined to determine the weight of the impact factors, and a consistency check was performed. The comprehensive evaluation index model was used to evaluate the intensity of freeze-thaw erosion in Tibet. The results show that freeze-thaw erosion is extensive, stretching over approximately $66.1 \%$ of Tibet. The problem is the most serious in Ngari Prefecture and Nagqu. However, mild erosion and moderate erosion, accounting for $37.1 \%$ and $25.0 \%$, respectively, of the total freeze-thaw erosion are the most widely distributed. The evaluation results for the freeze-thaw erosion was confirmed to be consistent with the actual situation. In brief, this study provided a new approach to evaluate the conditions of freeze-thaw erosion quantitively in Tibet.
\end{abstract}

Keywords: freeze-thaw erosion; cloud model; AHP; Tibet

\section{Introduction}

Freeze-thaw erosion occurs mainly in cold and high-latitude or high-altitude regions because of temperature changes [1]. During freeze-thaw erosion, the soil body or rock is mechanically broken because of volume changes, it is then transported, migrated, and piled up under the effects of gravity and other forces [1-3]. The third most frequently occurring type of erosion after water and wind erosion [4,5], freeze-thaw erosion is common in the areas of soil erosion in China. It is found mainly in the permafrost region at high altitudes, high latitudes, and extreme cold. According to the third national soil erosion remote-sensing survey data, the soil erosion area of 4.8474 million $\mathrm{km} 2$, of which freeze-thaw erosion accounts for 1.2782 million $\mathrm{km} 2$, is $13.31 \%$ of the total land area in China. It occurs mainly in the Northeast China, Northwest plateau, Qinghai-Tibet Plateau region [6-8]. In addition, the freeze-thaw erosion in Tibet is the most serious and extensive. It stretches across 0.905 million $\mathrm{km} 2$ and accounts for $70.8 \%$ of the country's freeze-thaw erosion [9-12]. It is one of the most important types of soil erosion in Tibet, and it is also one of the main ecological and environmental problems facing the region [7,10,13-15]. Freeze-thaw erosion has adversely affected agricultural production, animal husbandry, and the lives of the residents. It has undermined the safety of the roads and other projects, and it has seriously hindered the sustainable development of the regional economy and society [14,16-19]. Therefore, increased attention to the prevention and treatment of freeze-thaw erosion and the protection of Tibet's ecological environment is important. 
Over the years, scholars have conducted a great deal of valuable research on freeze-thaw erosion. This includes comprehensive and holistic research on the mechanisms behind freeze-thaw erosion $[7,11,18,20]$ and in-depth studies and discussions on specific areas in the region [21-23]. Qian et al. analyzed the formation characteristics and driving forces of freeze-thaw erosion in cold high-altitude zones [24]. Sun et al. summarized the effects of freeze-thaw on the physical and chemical properties of soil, wind erosion, and water erosion [25]. Jing et al. discussed the definition, types, and characteristics of freeze-thaw erosion, and they used AHP to explore the distribution and characteristics of freeze-thaw erosion in Heilongiiang Province [6,8,26]. Using geographic information system (GIS) technology, Zhang et al. analyzed and evaluated the freeze-thaw erosion in Sichuan Province [27]. Li et al. and Shi et al. used AHP to calculate the weight of the evaluation factors and GIS to realize the evaluation and analysis of freeze-thaw erosion in the three-river source region $[28,29]$. Lu et al. used AHP and the comprehensive evaluation index model to analyze the spatial distribution characteristics of freeze-thaw erosion in the Yalu Tsangpo River basin [30]. In recent years, microwave remote sensing technology has been applied to the study of freeze-thaw erosion [4,31-33]. On the basis of passive remove sensing, Chai et al. used two indices, the freeze-thaw cycling days per year and the phase transition water content per day, to classify and to evaluate freeze-thaw erosion in China [4,32]. The results indicate that passive microwave remote sensing is appropriate for monitoring freeze-thaw erosion. Kong and $\mathrm{Yu}$ applied the sensitivity of microwave remote sensing technology to soil moisture to identify a freeze-thaw state [33]. They also used AHP to develop an estimation model that is suitable for evaluating the extent of freeze-thaw erosion in the Silingco watershed in the wetlands of Northern Tibet.

Most studies have used AHP to determine the weight of the impact factors in freeze-thaw erosion [5,29,30,34-37]. The basic process for determining the weight of indicators by AHP is to select several of the important factors that affect a specific complex decision-making target. Experts in relevant fields are then invited to compare the impact factors through subjective factors, such as personal knowledge and experience, and to construct the evaluation index judgment matrix. Last, the weight of each impact factor is calculated $[38,39]$. The traditional AHP combines qualitative and quantitative methods; so it is simple, practical, and easy to operate. However, the importance of each impact factor depends on the subjective experience of individual experts. This oversimplifies the internal relationships among the factors. Accordingly, the final weight assignment result is subjective. Many scholars have acknowledged the problem. Thus, the AHP has been combined with other weight determination methods, such as an entropy method and principal component analysis (PCA), in the study of freeze-thaw erosion. On the basis of the traditional estimation model, Guo et al. adopted the microwave remote sensing indices: annual freeze-thaw cycle days and average diurnal phase-changed water content. They combined the AHP and an entropy method to calculate the weight of the freeze-thaw factor and established an evaluation model of freeze-thaw erosion in the Qinghai-Tibet Plateau [31]. Using the AHP and the PCA to determine the weight of the freeze-thaw factor, Guo et al. analyzed the spatial and temporal changes in freeze-thaw erosion in the three-river source region from 2000 to 2015 [40].

The cloud model is effective to achieve a transition between qualitative and quantitative uncertainties. It can be applied to decision support and comprehensive evaluation, and it increases the objectivity and effectiveness of qualitative evaluations [41,42]. Wang and Feng adopted the cloud model to express the preferences of decision-makers [43]. They proposed an improved AHP that is based on the judgment matrix scaled with the cloud model. Jia and $\mathrm{Xu}$ presented a weighted approach to seismic risk assessment on the basis of the cloud model and the AHP [44]. Samples were used to validate the method. By introducing the cloud model, Zhang et al. proposed an improved approach for the multi-hierarchal fuzzy comprehensive evaluation of reservoir-induced seismic risk [45]. This improved the robustness and visualization of the assessments results. Song et al. established a method for evaluating vulnerability severity on the basis of the cloud model and the AHP, which facilitated improvements in the processing efficiency of vulnerabilities [46]. Yang et al. proposed a cloud model-based approach for the practical risk assessment of mountain torrent disasters in Guizhou province [47]. 
On the basis of previous research, the current study has proposed the use of the cloud model and AHP to calculate the weight of evaluation factors. This was then used to conduct quantitative research on the intensity of freeze-thaw erosion in Tibet and to provide a reference for further research on its prevention and treatment. The study also offers suggestions for protecting the ecological environment.

\section{Data and methods}

\subsection{Study area}

Tibet is located on the southwestern border of China $\left(26^{\circ} 50^{\prime} \mathrm{N}-36^{\circ} 53^{\prime} \mathrm{N}, 78^{\circ} 25^{\prime}-99^{\circ} 06^{\prime} \mathrm{E}\right)$. It is bordered by Xinjiang in the north, Sichuan in the east, Qinghai in the northeast, and Yunnan in the southeast. It is approximately 1.202 million $\mathrm{km} 2$, accounting for approximately $1 / 8$ of the total land area of China. Surrounded by the Himalayas and the Kunlun and Tanggula Mountains, Tibet is the main part of the Qinghai-Tibet Plateau, the "roof of the world." It is located in the southwestern section of the Qinghai-Tibet Plateau and has an average elevation of more than 4,000 $\mathrm{m}$. The climate is unique, complex, and diverse. It is a unique highland climate with thin air and a complex geology. Generally, the northwest of Tibet is cold and dry, and the southeast is warm and humid. The distribution of the annual precipitation is extremely uneven, which gradually decreases from southeast to northwest. Because of the high altitude and low oxygen content, Tibet has the largest amount of solar radiation in China. It gradually increases from the southeast to the northwest. The annual variations in solar radiation are smallest in December and largest in May and June.

\subsection{Data Sources}

Shuttle Radar Topography Mission-Digital Elevation Model (STRM-DEM) data at $90 \mathrm{~m}$ resolution were provided by the Data Center for Resources and Environmental Sciences, Chinese Academy of Sciences (RESDC; http://www.resdc.cn). China's annual normalized difference vegetation index (NDVI) spatial distribution dataset (1998-2018) was derived from the RESDC [48]. The precipitation and temperature data for 1979-2013 were from climatologies at high resolution for the earth's land surface areas (CHELSA) [49,50].

\subsection{Research methods}

\subsubsection{Boundary definition of the freeze-thaw erosion region}

At present, the lower boundary of the ice edge zone or permafrost has been defined as the lower boundary of freeze-thaw erosion. On the basis of previous research, Zhang et al. proposed a method for defining the freeze-thaw erosion zone in Tibet [51]. The method, recognized by many scholars, has universal applicability to the definition of the range of freeze-thaw erosion zones in Tibet. The calculation equation (Equation [1]) for the lower boundary elevation of the freeze-thaw erosion area in Tibet is as follows:

$$
\mathrm{H}=\frac{66.3032-0.9197 \mathrm{X}-0.1438 \mathrm{Y}+2.5}{0.005596}-200,
$$

where $H$ refers to the altitude of the lower boundary of the freeze-thaw erosion region $(\mathrm{m}), X$ is the latitude $\left({ }^{\circ}\right)$, and $Y$ represents the longitude $\left(^{\circ}\right)$.

\subsubsection{Evaluation model of freeze-thaw erosion}

So far, the study of freeze-thaw erosion has adopted mainly the hierarchical weighting evaluation model, which is suitable for large-scale macro research. Different factors are measured in different units of measurement. The classification scheme is highly subjective. Classification schemes have a great influence on the evaluation results [29,52]; thus, standardization is needed to eliminate 
the unit differences in the variables. The variables can be processed using Equations (2) and (3) to change them into unit-less variables (0-1):

$$
\begin{aligned}
& I_{i}=\frac{I-I_{\text {min }}}{I_{\text {max }}-I_{\text {min }}} \times 100 \% \text { (positive), } \\
& I_{i}=\frac{I_{\text {max }}-I}{I_{\text {max }}-I_{\text {min }}} \times 100 \% \text { (negative), }
\end{aligned}
$$

where $I$ refers to the value of each factor, $I i$ is the standardized value of factor $I$, $I_{\text {min }}$ refers to the minimum value of factor $I$, and $I_{\max }$ is the maximum value of factor $I$. The larger $I i$ is, the more significant and intense are the effects of the selected freeze-thaw indices on freeze-thaw erosion. On the contrary, as $I i$ decreases, the significant weakens.

The comprehensive evaluation index model is as follows:

$$
\mathrm{FT}=\sum_{i=1}^{n} W_{i} I_{i} / \sum_{i=1}^{n} W_{i},
$$

where $F T$ is the freeze-thaw erosion index, Wi refers the weight of factor $i$, Ii refers to the value of evaluation factor $i$, and $n$ is the number of evaluation factors in freeze-thaw erosion.

\subsection{Evaluation factors}

Sun et al. [53] summarized the natural factors that contribute to freeze-thaw erosion: (1) temperature, given that the annual average ground temperature and ground temperature range in the region are decisive; (2) soil texture and soil moisture content; (3) vegetation, which can mitigate some of the effects; and (4) terrain and aspect, which have an influence on the type and degree of erosion. The operability and relevance of the pertinent indicators was considered on the basis of previous studies, and the freeze-thaw erosion evaluation system was constructed in relation to the following six indicators: annual temperature range, average annual precipitation, slope, aspect, vegetation coverage, and topographic relief. Previous studies have analyzed the effects of evaluation factors on freeze-thaw erosion; therefore, these approaches were not duplicated in this study. All of the classification factors are presented in Figure 1, and the values of the weightings are listed in Table 6.

It is worth noting that the edge effect is produced during the extraction of the terrain factors based on the digital elevation model (DEM). This creates inaccuracies in the statistical analysis of the directional data and, thus, affects the analysis and decision-making [54]. Accordingly, it was necessary to expand the range of the DEM. The indices were calculated with ArcGIS 10.2 software on the basis of the DEM dataset, and the spatial analysis tool was then used to extract the study area.

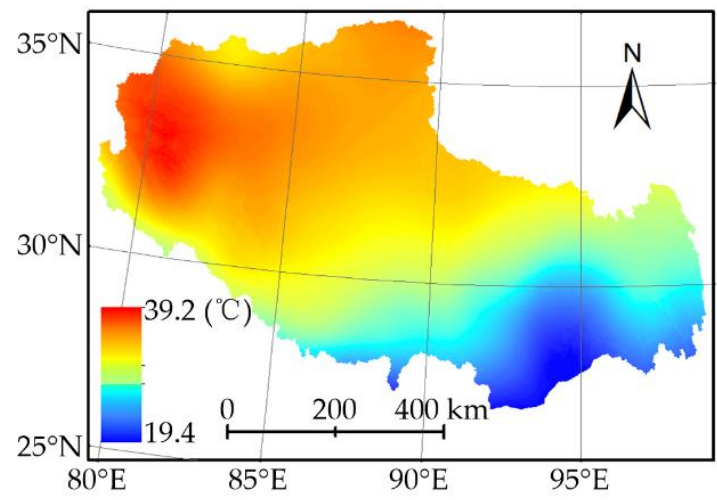

(a)

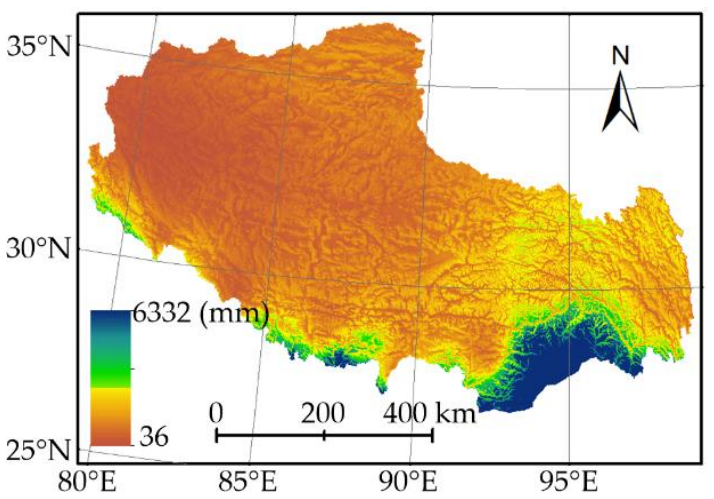

(b) 


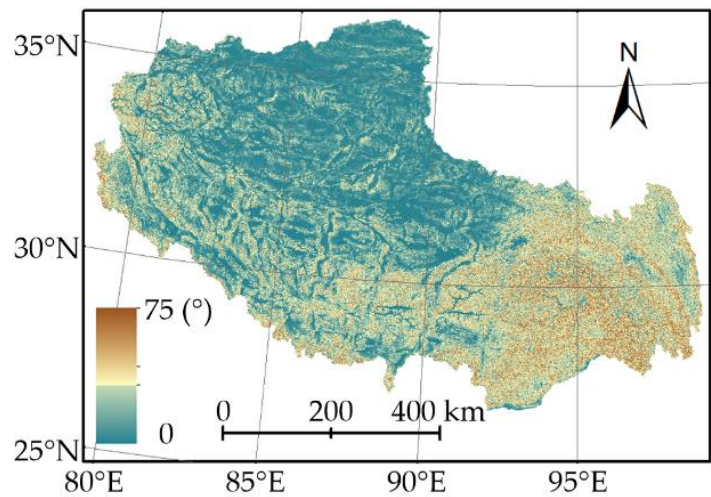

(c)

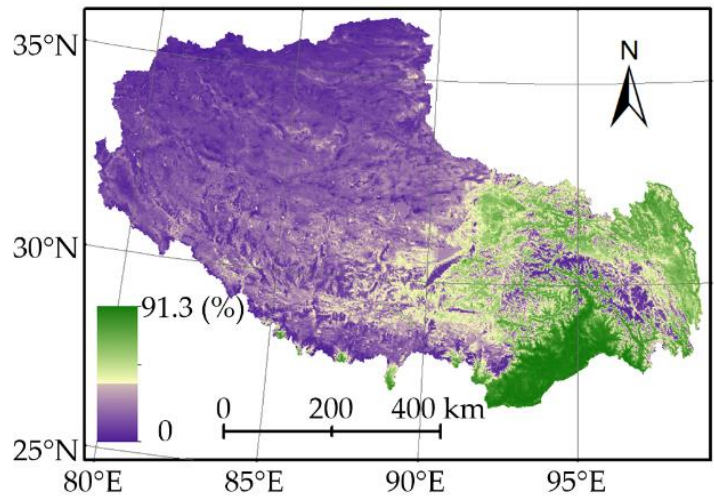

(e)

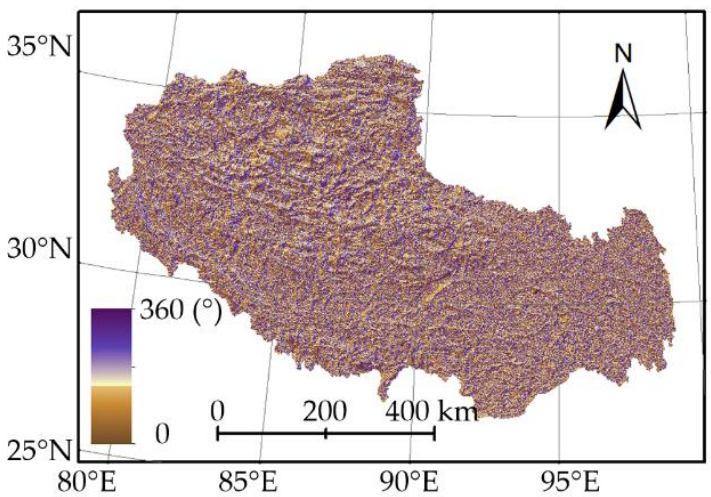

(d)

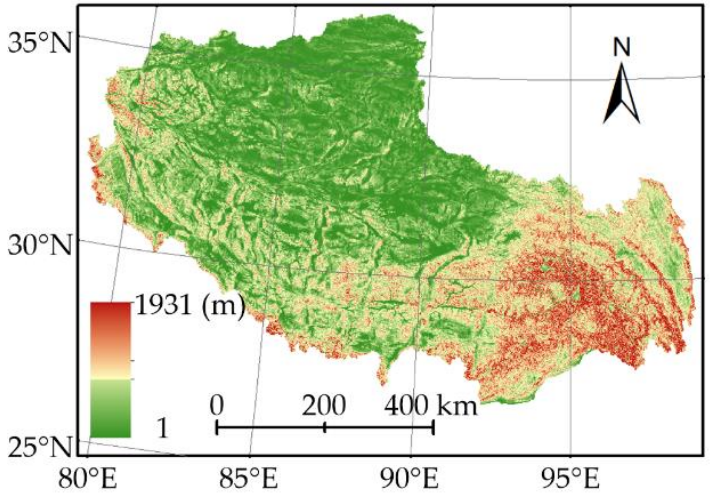

(f)

Figure 1. Distribution maps of various factors in Tibet: (a) annual temperature range; (b) average annual precipitation; (c) Slope; (d) aspect; (e) vegetation coverage; (f) topographic relief.

\section{Evaluation of freeze-thaw erosion intensity}

\subsection{Weight calculation of evaluation factors based on the cloud model and analytic hierarchy process}

The importance of the evaluation factors on freeze-thaw erosion is different. To more accurately reflect the effects on freeze-thaw erosion, each impact factor must be assigned a weight. Currently, the AHP is widely used in the evaluation of freeze-thaw erosion. However, the determination of the weighting is subjective because it is set artificially. At the same time, there is widespread uncertainty between qualitative concepts and quantitative data, especially fuzziness and randomness [55]. Because of the uncertainty and fuzziness of language, Li established a cloud model for the uncertainty transition from qualitative and quantitative [41,56]. It can integrate fuzziness and randomness to obtain more accurate descriptions. Therefore, the present study has proposed that the improved AHP, which is based on the cloud model, can synthesize the conclusions of multiple experts to overcome the deficiency of relying on the subjective experience of individual experts. This would provide evaluation results that are more accurate and objective.

\subsubsection{Feature importance profile based on cloud model}

The following scenario is offered: an universe $U=\{x\}(x=1,2,3, \ldots, 9)$ is represented by three digital characteristics: namely, expectation Ex, entropy En, and hyperentropy He. It is recorded as A (Ex, En, He). Expectation Ex, the mathematical expectation of the cloud drops belonging to a concept in the universe, can be regarded as the value that best represents the qualitative concept; entropy En is an uncertainty measurement of a qualitative concept; hyperentropy $\mathrm{He}$ is the uncertain degree of entropy En, namely the entropy of entropy [56-58]. To establish the importance decision scale, i.e., $E_{0}, E_{1}, \ldots$ Ex is equal to 1, 2, ... , 9, the following 9 cloud models were used: $A_{0}$ (Exo, Eno, Heo); $A_{1}$ (Ex1, En1, $\left.\mathrm{He}_{1}\right) ; \mathrm{A}_{2}\left(\mathrm{Ex}_{2}, \mathrm{En}_{2}, \mathrm{He}_{2}\right) ; \mathrm{A}_{3}\left(\mathrm{Ex}_{3}, \mathrm{En}_{3}, \mathrm{He}_{3}\right) ; \mathrm{A}_{4}\left(\mathrm{Ex}_{4}, \mathrm{En}_{4}, \mathrm{He}_{4}\right) ; \mathrm{A}_{5}\left(\mathrm{Ex}_{5}, \mathrm{En}_{5}, \mathrm{He}_{5}\right) ; \mathrm{A}_{6}\left(\mathrm{Ex}_{6}, \mathrm{En} 6\right.$, $\left.\mathrm{He}_{6}\right) ; \mathrm{A}_{7}\left(\mathrm{Ex}_{7}, \mathrm{En}_{7}, \mathrm{He}_{7}\right)$; and $\mathrm{A}_{8}\left(\mathrm{Ex}_{8}, \mathrm{En}_{8}, \mathrm{He}_{8}\right)$. The higher the value, the more important was the 
former than the latter [43]. The digital characteristics of the importance scale cloud model are presented in Table 1.

Table 1. Importance scale.

\begin{tabular}{|c|c|}
\hline Degree of importance & Definition \\
\hline $\mathrm{A}_{0}\left(\mathrm{Ex}_{0}, \mathrm{En}_{0}, \mathrm{He}_{0}\right), \mathrm{Ex}_{0}=1$ & Equal importance of two elements. \\
\hline $\mathrm{A}_{2}(\mathrm{Ex} 2, \mathrm{En} 2, \mathrm{He} 2), \mathrm{Ex}_{2}=3$ & $\begin{array}{l}\text { Weak importance of an element in comparison to the } \\
\text { other one. }\end{array}$ \\
\hline $\mathrm{A}_{4}\left(\mathrm{Ex}_{4}, \mathrm{En}_{4}, \mathrm{He}_{4}\right), \mathrm{Ex}_{4}=5$ & $\begin{array}{l}\text { Strong importance of an element in comparison to the } \\
\text { other one. }\end{array}$ \\
\hline $\mathrm{A}_{6}\left(\mathrm{Ex}_{6}, \mathrm{En}_{6}, \mathrm{He}_{6}\right), \mathrm{Ex}_{6}=7$ & $\begin{array}{l}\text { Certified importance of an element in comparison to the } \\
\text { other one. }\end{array}$ \\
\hline $\mathrm{A}_{8}(\mathrm{Ex} 8, \mathrm{En} 8, \mathrm{He} 8), \mathrm{Ex} 8=9$ & $\begin{array}{l}\text { Absolute importance of an element in comparison to the } \\
\text { other one. }\end{array}$ \\
\hline $\mathrm{Ex}_{1}=2, \mathrm{Ex}_{3}=4, \mathrm{Ex}_{5}=6, \mathrm{Ex}_{7}=8$ & Intermediate values between two appreciations. \\
\hline
\end{tabular}

The golden section method was adopted for calculating the En and He of each cloud model [44]. The calculation is as follows:

$$
\begin{gathered}
E n_{0}=E n_{2}=E n_{4}=E n_{6}=E n 4_{8}=0.382 \alpha\left(x_{\max }-x_{\min } / 6\right)=0.437, \\
E n_{1}=E n_{3}=E n_{5}=E n_{7}=E n_{8}=E n_{0} / 0.618=0.707, \\
H e_{1}=H e_{3}=H e_{5}=H e_{7}=H e_{0} / 0.618=0.118, \\
H e_{1}=H e_{3}=H e_{5}=H e_{7}=H e_{0} / 0.618=0.118,
\end{gathered}
$$

where $x_{\max }=9, x_{\min }=1, \alpha=0.858$, and $\alpha$ refers to the adjustment coefficient.

From the calculation, 9 judgment cloud models were obtained (Table 2). The importance of each element, on the basis of the cloud model in the AHP index system, is shown in Figure 2.

Table 2. Nine judgment cloud models.

\begin{tabular}{ccc}
\hline Degree of importance & Importance scale & Cloud model \\
\hline 1 & $\mathrm{Ex}_{0}=1$ & $\mathrm{~A}_{0}(1,0.437,0.073)$ \\
2 & $\mathrm{Ex}_{1}=2$ & $\mathrm{~A}_{1}(2,0.707,0.118)$ \\
3 & $\mathrm{Ex}_{2}=3$ & $\mathrm{~A}_{2}(3,0.437,0.073)$ \\
4 & $\mathrm{Ex}_{3}=4$ & $\mathrm{~A}_{3}(4,0.707,0.118)$ \\
5 & $\mathrm{Ex}_{4}=5$ & $\mathrm{~A}_{4}(5,0.437,0.073)$ \\
6 & $\mathrm{Ex}_{5}=6$ & $\mathrm{~A}_{5}(6,0.707,0.118)$ \\
7 & $\mathrm{Ex}_{6}=7$ & $\mathrm{~A}_{6}(7,0.437,0.073)$ \\
8 & $\mathrm{Ex}_{7}=8$ & $\mathrm{~A} 7(8,0.707,0.118)$ \\
9 & $\mathrm{Ex}_{8}=9$ & $\mathrm{~A} 8(9,0.437,0.073)$ \\
\hline
\end{tabular}




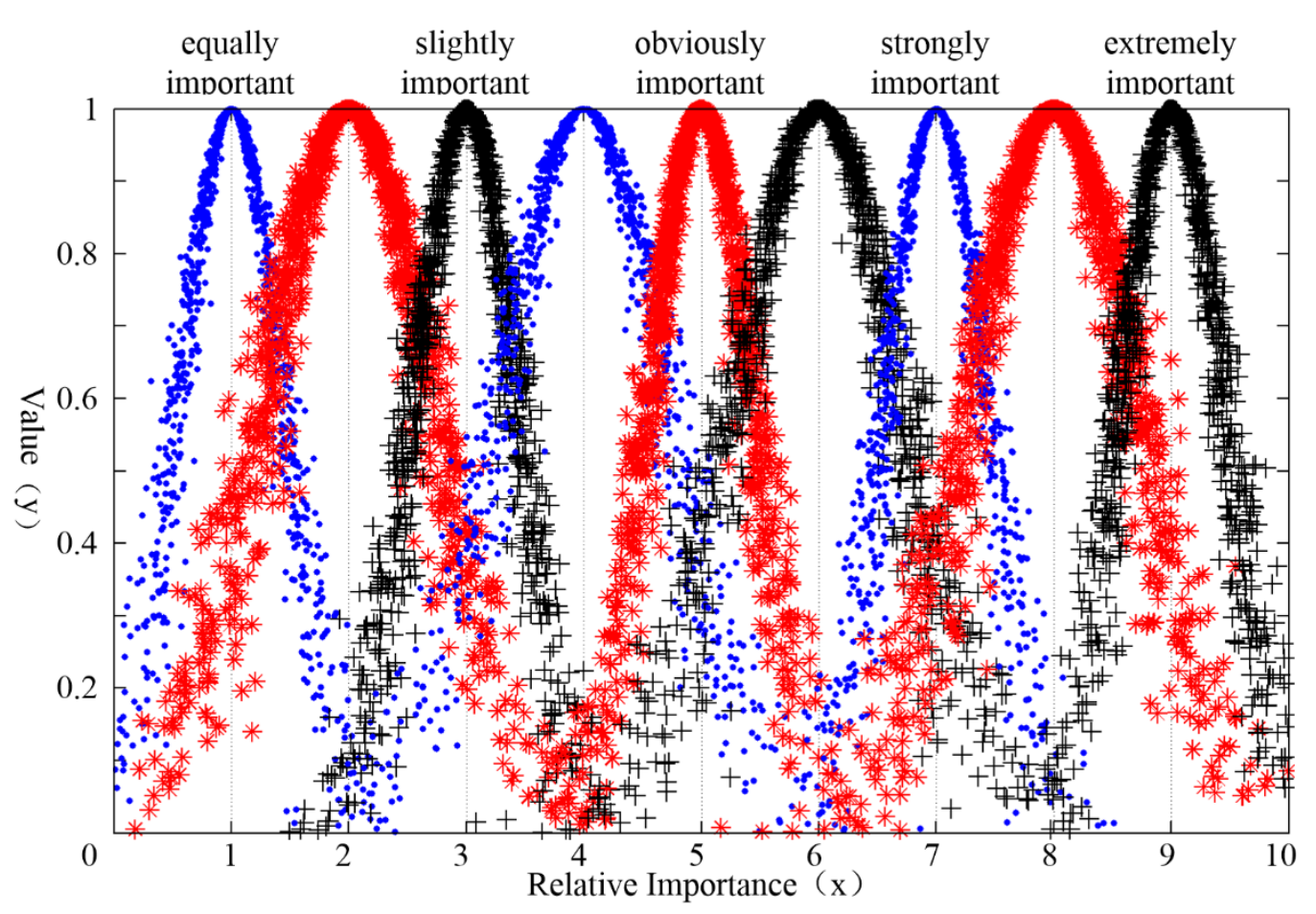

Figure 2. The nine cloud models that were used for determining the weight of each factor in the analytic hierarchy process index system.

\subsubsection{Acquisition of element importance based on group decision-making}

The aggregation preference of the floating cloud was used to judge the importance of element. The method is explained in the following scenario: an universe has two neighboring clouds: $\mathrm{C}_{1}\left(\mathrm{Ex}_{1}\right.$, $\left.\mathrm{En}_{1}, \mathrm{He}_{1}\right)$ and $\mathrm{C} 2\left(\mathrm{Ex}_{2}, \mathrm{En}_{2}, \mathrm{He}_{2}\right)$. A floating cloud, C (Ex, En, He) in Equations (9)-(11), can be generated between them [42,59-62]. Floating cloud C (Ex, En, He) expresses the blank language value of the qualitative concept described by clouds $\mathrm{C} 1$ and $\mathrm{C} 2$ [63]. When floating cloud $\mathrm{C}$ is floating towards $\mathrm{C} 1$, it will be increasingly affected by $\mathrm{C} 1$ but increasingly less affected by $\mathrm{C} 2$ until it is totally overlapped at the position of $C 1$, and vice versa [43,44,64-66]:

$$
\begin{gathered}
E x=\beta_{1} E x_{1}+\beta_{2} E x_{2}, \\
\mathrm{En}=\frac{E n_{1}\left(E x_{2}-E x\right)+E n_{2}\left(E x-E x_{1}\right)}{E x_{2}-E x_{1}}, \\
\mathrm{He}=\frac{H e_{1}\left(E x_{2}-E x\right)+H e_{2}\left(E x-E x_{1}\right)}{E x_{2}-E x_{1}},
\end{gathered}
$$

where $\beta_{1}$ refers to the adjustment coefficient and its value is determined by experts on the basis of specific circumstances. In the following, $\beta_{1}=k 1 /(\mathrm{k} 1+\mathrm{k} 2), \beta_{2}=k 2 /(\mathrm{k} 1+\mathrm{k} 2)$, $\mathrm{ki}(\mathrm{i}=1,2)$ represents the number of times the ith cloud model has been aggregated, and $\beta_{1}+\beta_{2}=1$. If the expert considers that there is no need to intervene in the aggregation activity, then $\beta_{1}=\beta_{2}=0.5$.

If there are $m$ neighboring clouds, i.e., $\mathrm{C}_{1}\left(\mathrm{Ex}_{1}, \mathrm{En}_{1}, \mathrm{He}_{1}\right), \mathrm{C}_{2}\left(\mathrm{Ex}_{2}, \mathrm{En}_{2}, \mathrm{He}_{2}\right), \ldots, \mathrm{C}_{\mathrm{m}}\left(\mathrm{Ex}_{\mathrm{m}}, \mathrm{En}_{\mathrm{m}}, \mathrm{He}_{\mathrm{m}}\right)$, in an universe, a floating cloud, namely $\mathrm{C}(\mathrm{Ex}, \mathrm{En}, \mathrm{He})$, in a qualitative concept can be generated by aggregating m clouds (Equations [12]-[14]). C (Ex, En, He) will be affected by the synthetic effect of the m clouds $[66,67]$.

$$
\mathrm{Ex}=\beta_{1} E x_{1}+\beta_{2} E x_{2}+\ldots+\beta_{m} E x_{m},
$$




$$
\begin{gathered}
\mathrm{En}=\frac{\beta_{1} E n_{1} E x_{1}+\beta_{2} E n_{2} E x_{2}+\ldots+\beta_{m} E n_{m} E x_{m}}{\beta_{1} E x_{1}+\beta_{2} E x_{2}+\ldots+\beta_{m} E x_{m}}, \\
\mathrm{He}=\sqrt{H e_{1}^{2}+H e_{2}^{2}+\ldots H e_{m}^{2}},
\end{gathered}
$$

where $\beta_{\mathrm{m}}$ refers to the adjustment coefficient and its value is determined by experts on the basis of specific circumstances. In the following, $\beta_{1}=\frac{k_{1}}{k_{1}+k_{2}+\ldots+k_{m}}, \quad \beta_{2}=\frac{k_{2}}{k_{1}+k_{2}+\ldots+k_{m}}, \ldots$, $\beta_{m}=\frac{k_{m}}{k_{1}+k_{2}+\ldots+k_{m}}, \mathrm{ki}(\mathrm{i}=1,2, \ldots, \mathrm{m})$ represents the number of times the ith cloud model has been aggregated, and $\beta_{1}+\beta_{2}+\ldots+\beta_{m}=1$. If the expert considers that there is no need to intervene in the aggregation activity, then $\beta_{1}=\beta_{2}=\ldots=\beta_{m}=\frac{1}{m}$.

3.1.3 Cloud model and analytic hierarchy process based on scale judgment matrix

On the basis of group decision-making, the judgment matrix for the comparison of the importance of each element based on cloud model was constructed as follows:

$$
\left\{\begin{array}{cccc}
a_{11} & a_{12} & \ldots & a_{1 n} \\
a_{21} & a_{22} & \ldots & a_{2 n} \\
\ldots & \ldots & \ldots & \ldots \\
a_{n 1} & a_{n 2} & \ldots & a_{n n}
\end{array}\right\}=\left\{\begin{array}{cccc}
A_{11}(1,0,0) & A_{12}\left(\mathrm{Ex}_{12}, \mathrm{En}_{12}, \mathrm{He}_{12}\right) & \ldots & A_{1 n}\left(\mathrm{Ex}_{1 n}, \mathrm{En}_{1 n}, \mathrm{He}_{1 n}\right) \\
A_{21}\left(\mathrm{Ex}_{21}, \mathrm{En}_{21}, \mathrm{He}_{21}\right) & A_{22}(1,0,0) & \ldots & A_{2 n}\left(\mathrm{Ex}_{2 n}, \mathrm{En}_{2 n}, \mathrm{He}_{2 n}\right) \\
\ldots & \ldots & \ldots & \ldots \\
A_{n 1}\left(\mathrm{Ex}_{n 1}, \mathrm{En}_{n 1}, \mathrm{He}_{n 1}\right) & A_{n 2}\left(\mathrm{Ex}_{n 2}, \mathrm{En}_{n 2}, \mathrm{He}_{n 2}\right) & \ldots & A_{n n}(1,0,0)
\end{array}\right\}
$$

where the elements on the diagonal $\mathrm{Aij}=(1,0,0$; note: $\mathrm{i}=\mathrm{j})$ mean that the same factors are of equal importance. If the latter factor is more important than the former, then the importance of the reciprocal scale is expressed as $a_{i j}=\frac{1}{a_{j i}}$ (Equation [16]).

$$
a_{i j}=A_{i j}=\frac{1}{a_{j i}}=\frac{1}{A_{j i}}=\frac{1}{A_{j i}\left(\mathrm{E}_{x}, \mathrm{E}_{n}, \mathrm{H}_{e}\right)}=\left(\frac{1}{\mathrm{E}_{x}}, \frac{\mathrm{E}_{\mathrm{n}}}{\left(\mathrm{E}_{x}\right)^{2}}, \frac{H_{e}}{\left(\mathrm{E}_{x}\right)^{2}}\right),
$$

The square root method is used to calculate the relative weights of the expectation, fuzziness, and randomness of the elements. If there are $m$ neighboring clouds $C_{1}\left(E x_{1}, E_{1}, H_{1}\right), C_{2}\left(E_{2}, E n_{2}\right.$, $\left.\mathrm{He}_{2}\right), \ldots, \mathrm{C}_{\mathrm{m}}\left(\mathrm{Ex}_{\mathrm{m}}, \mathrm{En}_{\mathrm{m}}, \mathrm{He}_{\mathrm{m}}\right)$ in an universe, the multiplication operation in cloud model computing is introduced, and the calculated result is C (Ex, En, He), where

$$
\begin{gathered}
E \mathrm{x}=E x_{1} E x_{2} \ldots E x_{n}, \\
E \mathrm{n}=\left|E x_{1} E x_{2} \ldots E x_{n}\right| \cdot \sqrt{\left(\frac{E n_{1}}{E x_{1}}\right)^{2}+\left(\frac{E n_{2}}{E x_{2}}\right)^{2}+\ldots+\left(\frac{E n_{n}}{E x_{n}}\right)^{2}}, \\
H \mathrm{e}=\left|E x_{1} E x_{2} \ldots E x_{n}\right| \cdot \sqrt{\left(\frac{H e_{1}}{E x_{1}}\right)^{2}+\left(\frac{H e_{2}}{E x_{2}}\right)^{2}+\ldots+\left(\frac{H e_{n}}{E x_{n}}\right)^{2}} .
\end{gathered}
$$

Thus, $W_{i}^{(0)}\left(\mathrm{Ex}_{i}^{(0)}, \mathrm{En}_{i}^{(0)}, H e_{i}^{(0)}\right)$ is obtained, and the results are as follows (Equations [20]-[22]): 


$$
\begin{aligned}
& E \mathrm{x}_{i}^{(0)}=\frac{E \mathrm{x}_{i}}{\sum E \mathrm{x}_{i}}=\frac{\left(\prod_{j=1}^{n} E \mathrm{x}_{i j}\right)^{\frac{1}{n}}}{\sum_{i=1}^{n}\left(\prod_{j=1}^{n} E \mathrm{x}_{i j}\right)^{\frac{1}{n}}} \\
& E \mathrm{n}_{i}^{(0)}=\frac{E \mathrm{n}_{i}}{\sum E \mathrm{n}_{i}}=\frac{\left\{\left(\prod_{j=1}^{n} E \mathrm{x}_{i j}\right) \sqrt{\sum_{j=1}^{n}\left(\frac{E n_{i j}}{E x_{i j}}\right)^{2}}\right\}^{\frac{1}{n}}}{\sum_{i=1}^{n}\left\{\left(\prod_{j=1}^{n} E \mathrm{x}_{i j}\right) \sqrt{\sum_{j=1}^{n}\left(\frac{E n_{i j}}{E x_{i j}}\right)^{2}}\right\}^{\frac{1}{n}}}, \\
& H \mathrm{e}_{i}^{(0)}=\frac{H e_{i}}{\sum H e_{i}}=\frac{\left\{\left(\prod_{j=1}^{n} E \mathrm{x}_{i j}\right) \sqrt{\sum_{j=1}^{n}\left(\frac{H e_{i j}}{E x_{i j}}\right)^{2}}\right\}^{\frac{1}{n}}}{\sum_{i=1}^{n}\left\{\left(\prod_{j=1}^{n} E \mathrm{x}_{i j}\right) \sqrt{\sum_{j=1}^{n}\left(\frac{H e_{i j}}{E x_{i j}}\right)^{2}}\right\}^{\frac{1}{n}}},
\end{aligned}
$$

The desired consistency check is performed by using the consistency indices $\mathrm{C}$ and R. The formula is as follows (Equations [23]-[24]):

$$
\begin{gathered}
C=\frac{\lambda_{\max }-n}{n-1}, \\
\lambda_{\max } \approx \frac{1}{n} \sum_{i=1}^{n}\left(\frac{\sum_{j=1}^{n} E x_{i j} W_{i 1}}{W_{1 j}}\right) .
\end{gathered}
$$

The consistency ratio (CR) is obtained by calculation, and the CR is required to be less than 0.1 (Equation [25]),

$$
C R=\frac{C}{R}<0.1
$$

where $\mathrm{R}$ is the average of the consistency index of the same-order random judgment matrix.

3.1.4 Weight assignment of evaluation factors based on cloud model and analytic hierarchy process

On the basis of previous studies, the judgment matrix of the index to the freeze-thaw erosion intensity can be determined according to the relative importance of each evaluation index for freeze-thaw erosion intensity. The weight is then calculated through the AHP, and the consistency check is then performed. Two comparison matrices, P1 and P2, are obtained (Table 3).

Table 3. Comparison matrix of evaluation factor.

$\begin{array}{ll}\text { P1 } & \text { P2 }\end{array}$

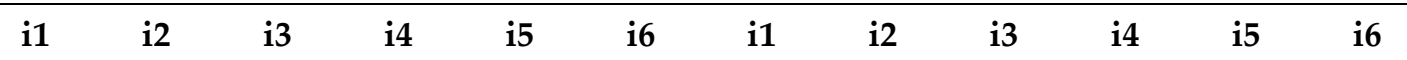




\begin{tabular}{ccccccccccccc}
\hline i1 & 1 & 1 & $1 / 2$ & 3 & 2 & 1 & 1 & 2 & $1 / 3$ & 4 & 3 & 1 \\
i2 & 1 & 1 & $1 / 3$ & 3 & 2 & $1 / 2$ & $1 / 2$ & 1 & $1 / 4$ & 2 & 1 & $1 / 2$ \\
i3 & 2 & 3 & 1 & 4 & 3 & 2 & 3 & 4 & 1 & 5 & 2 & 3 \\
i4 & $1 / 3$ & $1 / 3$ & $1 / 4$ & 1 & $1 / 2$ & $1 / 4$ & $1 / 4$ & $1 / 2$ & $1 / 5$ & 1 & $1 / 3$ & $1 / 5$ \\
i5 & $1 / 2$ & $1 / 2$ & $1 / 3$ & 2 & 1 & $1 / 3$ & $1 / 3$ & 1 & $1 / 2$ & 3 & 1 & $1 / 2$ \\
i6 & 1 & 2 & $1 / 2$ & 4 & 3 & 1 & 1 & 2 & $1 / 3$ & 5 & 2 & 1 \\
\hline
\end{tabular}

Note: i1 refers to the annual temperature range, i2 refers to the average annual precipitation, i3 refers to the slope, i4 refers to the aspect, i5 refers to the vegetation coverage, and i6 refers to the topographic relief.

On the basis of the above comparison matrix, the language judgment scale of Factors i1 and i2 based on the cloud model can be obtained as $\mathrm{A} 1=(1,0,0)$ and $\mathrm{A} 2=(2,0.437,0.073)$, respectively. After the aggregation, the cloud model of importance judgment between i1 and i2 is (1.5, 0.219, 0.037). Similarly, according to Equations (9)-(11), the judgment matrix can be obtained through aggregation (Table 4). 
Table 4. Judgment matrix.

\begin{tabular}{ccccccc}
\hline Index & i1 & i2 & i3 & i4 & i5 & i6 \\
\hline i1 & $(1,0,0)$ & $(1.5,0.219,0.037)$ & $(0.417,0.094,0.016)$ & $(3.5,0.572,0.096)$ & $(2.5,0.572,0.096)$ & $(1,0,0)$ \\
i2 & $(0.75,0.055,0.009)$ & $(1,0,0)$ & $(0.292,0.053,0.009)$ & $(2.5,0.572,0.096)$ & $(1.5,0.219,0.037)$ & $(0.5,0.109,0.018)$ \\
i3 & $(2.5,0.572,0.096)$ & $(3.5,0.572,0.096)$ & $(1,0,0)$ & $(4.5,0.572,0.096)$ & $(2.5,0.572,0.096)$ & $(2.5,0.572,0.096)$ \\
i4 & $(0.292,0.053,0.009)$ & $(0.417,0.094,0.016)$ & $(0.225,0.028,0.005)$ & $(1,0,0)$ & $(0.417,0.094,0.016)$ & $(0.225,0.028,0.005)$ \\
i5 & $(0.417,0.164,0.048)$ & $(0.75,0.125,0.042)$ & $(0.417,0.094,0.016)$ & $(2.5,0.572,0.096)$ & $(1,0,0)$ & $(0.417,0.094,0.016)$ \\
i6 & $(1,0,0)$ & $(2,0.437,0.073)$ & $(0.417,0.164,0.048)$ & $(4.5,0.572,0.096)$ & $(2.5,0.572,0.096)$ & $(1,0,0)$ \\
\hline
\end{tabular}

2 Note: i1 refers to the annual temperature range, i2 refers to the average annual precipitation, i3 refers to the slope, i4 refers to the aspect, i5 refers to the vegetation coverage, and i6 3 refers to the topographic relief. 
The relative weight $W_{i}^{(0)}$ is calculated according to Equations (17)-(22):

$$
E \mathrm{x}_{1}=(1 \times 1.5 \times 0.417 \times 3.5 \times 2.5 \times 1)^{\frac{1}{6}}=1.327
$$

Similarly, $\mathrm{Ex}_{2}=0.862, \mathrm{Ex}_{3}=2.503, \mathrm{Ex}_{4}=0.37, \mathrm{Ex}_{5}=0.717, \mathrm{Ex}_{6}=1.452$.

$$
E x_{1}{ }^{(0)}=1.327 /(1.327+0.862+2.053+0.37+0.717+1.452)=0.184 \text {, }
$$

As such, $\operatorname{Ex}_{2}(0)=0.119, \operatorname{Ex}_{3}(0)=0.346, \operatorname{Ex}_{4}(0)=0.051, \operatorname{Ex}_{5}(0)=0.099, \operatorname{Ex}_{6}(0)=0.201$.

$$
E \mathrm{n}_{1}=\left\{(1 \times 1.5 \times 0.417 \times 3.5 \times 2.5 \times 1)\left(\left(\frac{0}{1}\right)^{2}+\left(\frac{0.219}{1.5}\right)^{2}+\left(\frac{0.094}{0.417}\right)^{2}+\left(\frac{0.572}{3.5}\right)^{2}+\left(\frac{0.572}{2.5}\right)^{2}+\left(\frac{0}{1}\right)^{2}\right)^{\frac{1}{2}}\right\}^{\frac{1}{6}}=1.134
$$

In like manner, $\mathrm{En}_{2}=0.74, \mathrm{En}_{3}=2.189, \mathrm{En}_{4}=0.318, \mathrm{En}_{5}=0.655, \mathrm{En}_{6}=1.303$.

$$
E_{1}^{(0)}=1.134 /(1.134+0.74+2.189+0.318+0.655+1.303)=0.179
$$

In the same way, $\operatorname{En}_{2}\left({ }^{(0)}=0.117, \operatorname{En}_{3}(0)=0.345, \operatorname{En}_{4}(0)=0.005, \operatorname{En}_{5}(0)=0.099, \operatorname{En}_{6}{ }^{(0)}=2.06\right.$. $^{(0)}$

$$
H e_{1}=\left\{(1 \times 1.5 \times 0.417 \times 3.5 \times 2.5 \times 1)\left(\left(\frac{0}{1}\right)^{2}+\left(\frac{0.037}{1.5}\right)^{2}+\left(\frac{0.016}{0.417}\right)^{2}+\left(\frac{0.096}{3.5}\right)^{2}+\left(\frac{0.096}{2.5}\right)^{2}+\left(\frac{0}{1}\right)^{2}\right)^{\frac{1}{2}}\right\}^{\frac{1}{6}}=0.841
$$

Therefore, $\mathrm{He}_{2}=0.549, \mathrm{He}_{3}=1.624, \mathrm{He}_{4}=0.236, \mathrm{He}_{5}=0.519, \mathrm{He}_{6}=1.032$.

$$
H \mathrm{e}_{1}^{(0)}=0.841 /(0.841+0.549+1.624+0.236+0.519+1.032)=0.175
$$

Similarly, $\mathrm{He}_{2}^{(0)}=0.114, \mathrm{He}_{3}^{(0)}=0.338, \mathrm{He}_{4}^{(0)}=0.049, \mathrm{He}_{5}^{(0)}=0.108, \mathrm{He}_{6}{ }^{(0)}=0.215$.

Last, the relative weights are obtained by sorting (Table 5).

Table 5. Calculation of importance.

\begin{tabular}{cc}
\hline $\mathbf{W}_{\mathbf{i}}$ & $\mathbf{W}_{\mathbf{i}}{ }^{(\mathbf{0})}$ \\
\hline$(1.327,1.134,0.841)$ & $(0.184,0.179,0.175)$ \\
$(0.862,0.74,0.549)$ & $(0.119,0.117,0.114)$ \\
$(2.503,2.189,1.624)$ & $(0.346,0.345,0.338)$ \\
$(0.37,0.318,0.236)$ & $(0.051,0.05,0.049)$ \\
$(0.717,0.655,0.519)$ & $(0.099,0.103,0.108)$ \\
$(1.452,1.303,1.032)$ & $(0.201,0.206,0.215)$ \\
\hline
\end{tabular}

The consistency check of expectation is calculated as follows:

$$
\begin{gathered}
{\left[\begin{array}{cccccc}
1 & 1.5 & 0.417 & 3.5 & 2.5 & 1 \\
0.75 & 1 & 0.292 & 2.5 & 1.5 & 0.5 \\
2.5 & 3.5 & 1 & 4.5 & 2.5 & 2.5 \\
0.292 & 0.417 & 0.225 & 1 & 0.417 & 0.225 \\
0.417 & 0.75 & 0.417 & 2.5 & 1 & 0.417 \\
1 & 2 & 0.417 & 4.5 & 2.5 & 1
\end{array}\right]\left[\begin{array}{c}
1.327 \\
0.862 \\
2.503 \\
0.37 \\
0.717 \\
1.452
\end{array}\right]=\left[\begin{array}{c}
8.202 \\
5.314 \\
15.926 \\
2.305 \\
4.489 \\
9.003
\end{array}\right],} \\
\lambda_{\max } \approx \frac{1}{n} \sum_{i=1}^{n} \frac{\sum_{j=1}^{n} E x_{i j} W_{i 1}}{W_{1 j}}=\left(\frac{8.202}{1.327}+\frac{5.314}{0.862}+\frac{15.926}{2.503}+\frac{2.305}{0.37}+\frac{4.489}{0.717}+\frac{9.003}{1.452}\right) / 6=6.233, \\
C=\frac{\lambda \max }{n-1}=\frac{6.233-6}{6-1}=0.047, \\
C R=\frac{C}{R}=\frac{0.047}{1.26}=0.037<0.1 .
\end{gathered}
$$


According to the consistency check, $C R(C R=0.037)$ is less than 0.1 , and the judgment matrix satisfies consistency. The weight vector, i.e., the weight of all the indices of freeze-thaw erosion, is shown in Table 6.

Table 6. Weighting of freeze-thaw erosion indicators.

\begin{tabular}{ccccccc}
\hline Index & (1) ATR & (2) ANP & (3) Slope & (4) Aspect & (5) VC & (6) TR \\
\hline Weight & 0.184 & 0.119 & 0.346 & 0.051 & 0.099 & 0.201
\end{tabular}

Note: (1) = ATR, annual temperature range; (2) = ANP, average annual precipitation; (3) = slope; (4) = aspect; (5) $=\mathrm{VC}$, vegetation coverage; and $(6)=\mathrm{TR}$, topographic relief

\subsection{Evaluation of freeze-thaw erosion intensity}

The distribution map of freeze-thaw erosion intensity in Tibet was developed through the combination of ArcGIS 10.2 software and the comprehensive evaluation model. The freeze-thaw erosion intensity index was 0.109-0.648. To facilitate the analysis of the spatial pattern of freeze-thaw erosion, on the basis of the distribution map, the freeze-thaw erosion intensity comprehensive index was divided into slight erosion, mild erosion, moderate erosion, intensive erosion, and severe erosion by the natural breaks method. ArcGIS software was used in this process (see Figure 3).

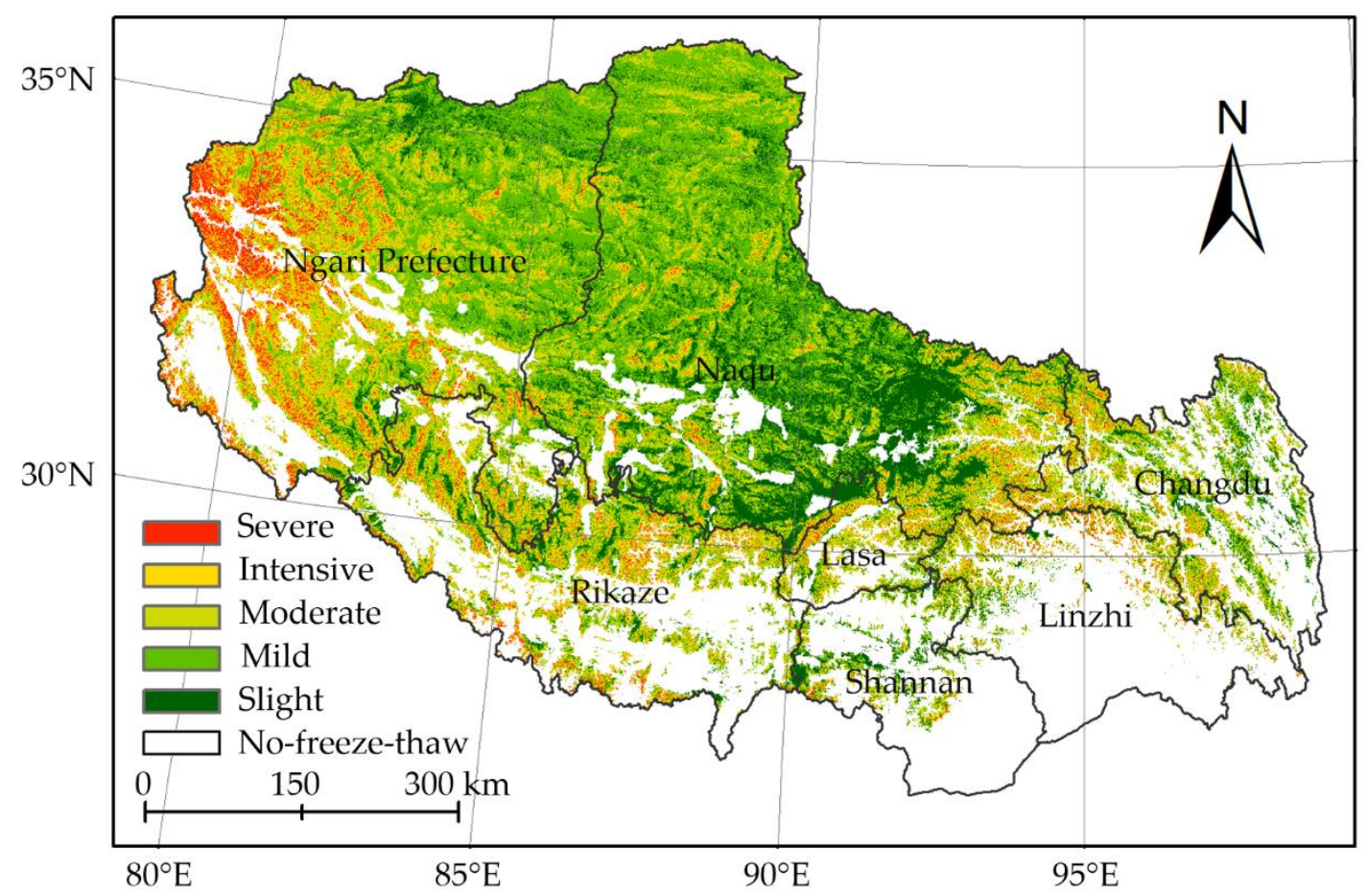

Figure 3. Grading map of freeze-thaw erosion intensity in Tibet.

The area of freeze-thaw erosion intensity was calculated with ArcGIS software (see Figure 4). 


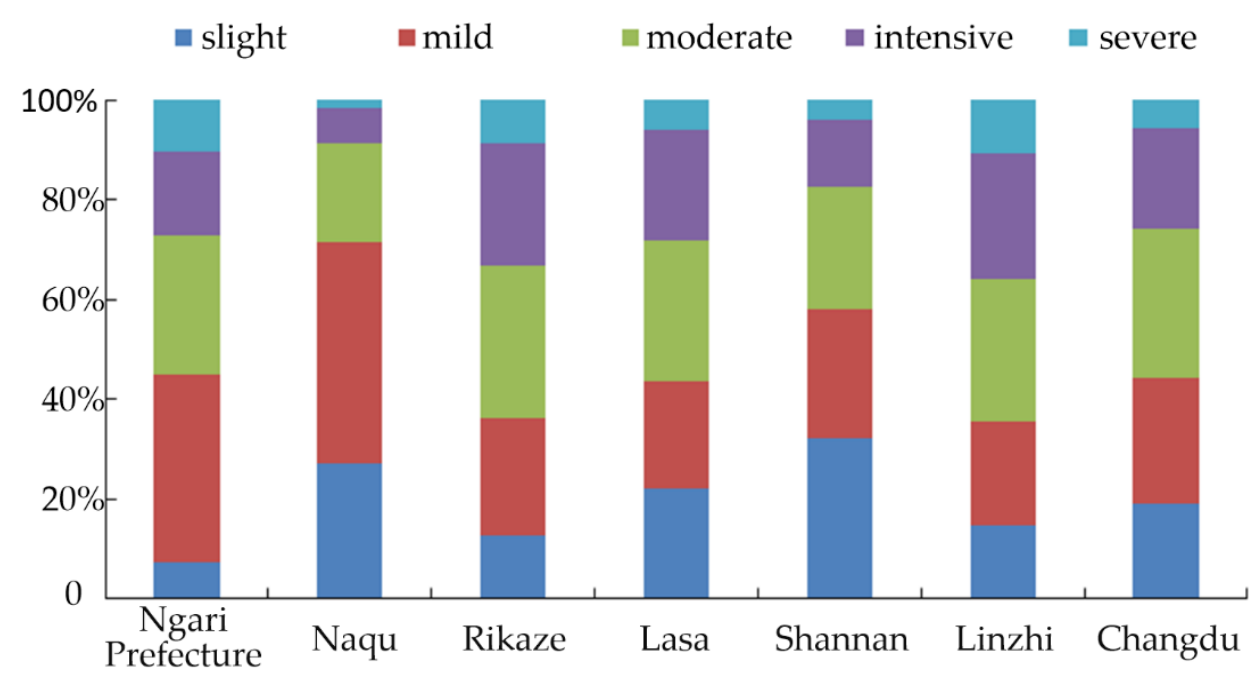

Figure 4. Freeze-thaw erosion levels in Tibet.

Figures 3 and 4 indicate that freeze-thaw erosion is widely distributed in Tibet. Concentrated mostly in Ngari Prefecture and Naqu, it stretches over approximately $66.1 \%$ of the total area of Tibet. Mild erosion and moderate erosion, $37.1 \%$ and $25.0 \%$ of the total area, respectively, are the most widely distributed. Slight erosion, which is distributed mainly in Naqu, Shannan, and Lasa, accounts for $17.7 \%$ of the area of freeze-thaw erosion. Intensive erosion, which accounts for $14.2 \%$ of the total area of freeze-thaw erosion, is distributed mainly in Rikaze, Lasa, Linzhi, and Changdu. Severe erosion, which is concentrated mainly in Ngari Prefecture, Linzhi, and Rikaze, accounts for $6.0 \%$ of the freeze-thaw erosion area. The no-freeze-thaw region is mainly concentrated in Rikaze, Shannan, and Linzhi.

\section{Validation of results}

To evaluate the efficacy of the results, previous studies on freeze-thaw erosion in Tibet were used as the basis for comparative verification. In addition, 196 sampling points were collected from high-definition Google Earth images to evaluate the experimental results through visual interpretation. Zhang et al. $[1,34,35,68]$ and $\mathrm{Li}$ et al. [16] have done a great deal of research on freeze-thaw erosion in Tibet, which took place relatively early. Regarding the spatial distribution, the results of this paper confirm those of previous studies. Recently, Guo et al. [5,31] conducted research on freeze-thaw erosion on the Tibetan plateau. A comparison of the freeze-thaw erosion distribution maps obtained in that and the present study indicates that the studies achieved the same experimental results.

On the basis of previous studies [30,31,40], an error analysis matrix was constructed from the observation points collected from Google images and the evaluation results of this paper. This facilitated the analysis of the accuracy of various freeze-thaw erosion intensity values (see Table 7).

Table 7. Error matrix of freeze-thaw erosion categories.

\begin{tabular}{ccccccccc}
\hline \multirow{2}{*}{$\begin{array}{c}\text { Erosion } \\
\text { severity }\end{array}$} & \multicolumn{5}{c}{ Evaluation results for freeze-thaw erosion } & \multirow{2}{*}{ Total } & Evaluation \\
\cline { 2 - 5 } & Slight & Mild & Moderate & Intensive & Severe & & accuracy \\
\hline Slight & 13 & 1 & 1 & 0 & 1 & 16 & $81 \%$ \\
Mild & 2 & 50 & 0 & 1 & 1 & 54 & $93 \%$ \\
Moderate & 0 & 2 & 60 & 2 & 2 & 66 & $91 \%$ \\
Intensive & 3 & 2 & 2 & 30 & 2 & 39 & $77 \%$ \\
Severe & 0 & 1 & 1 & 1 & 18 & 21 & $86 \%$ \\
\hline
\end{tabular}




$\begin{array}{llllllll}\text { Total } & 18 & 56 & 64 & 34 & 24 & 196 & -\end{array}$

As is shown in Table 7, the evaluation accuracy, $0.77-0.93$, demonstrates the validity of the classification. The values for mild erosion were the most precise. The accuracy of the values for intensive erosion was much lower. Nevertheless, the overall precision was $87.2 \%$, thus confirming the high efficiency and accuracy of this freeze-thaw erosion model for Tibet.

\section{Conclusion}

In this study, the weight of the evaluation factors was calculated by an improved AHP based on the cloud model. In addition, the freeze-thaw erosion intensity index for Tibet was evaluated by a combination of ArcGIS software and a comprehensive evaluation model. The results indicate that freeze-thaw erosion is widely distributed in Tibet, which is mainly concentrated in Ngari Prefecture and Naqu. Mild erosion and moderate erosion, which are concentrated in Ngari Prefecture and Naqu, are the most widely distributed. Upon verification, the evaluation results were found to be consistent with the actual.

This study has introduced the cloud model theory. In addition, it used the aggregation algorithm of the cloud model to synthesize the opinions of many experts on the process of determining factor weights. This overcomes the deficiencies of traditional AHP, which relies on the subjective experience of individual experts. This method allows for a more accurate and objective description of the fuzziness and randomness of the impact factors in freeze-thaw erosion. Thus, the weight of each factor in freeze-thaw erosion evaluation can be objectively reflected, and the objectivity and reliability of evaluations can be improved. The results of the evaluation were consistent with the reality. This study is of great significance to the study of freeze-thaw erosion. It provides scientific data to support soil and water conservation and ecological environment protection in freeze-thaw erosion areas.

Author Contributions: Taoying Hu collected and processed the data, performed analysis and wrote the original draft of the paper. Junfu Fan conceived and designed the study and methods, reviewed and edited the paper. Xiao Yu, Yuke Zhou, Peng Zhang and Liusheng Han contributed to analysis and interpretation of the data.

Funding: This research was funded in part by the National Key Research and Development Program of China under Grant 2017YFB0503500, in part by the National Natural Science Foundation of China under Grant 41601478, in part by the Young Teacher Development Support Program of Shandong University of Technology under Grant 4072-115016.

Acknowledgment: The authors would like to thank Dr. Bing Guo for providing valuable suggestions to the results verification process of this paper.

Conflicts of Interest: The authors declare no conflict of interest.

\section{References}

1. Zhang, J.; Yang, Y.; Liu, S. Classification and assessment of freeze-thaw erosion in Tibet, China. Wuhan University Journal of Natural Sciences 2005, 10, 635-640.

2. Tang, K. Soil and water conservation in China. Science Press 2003, 3-27.

3. Eigenbrod, K.D. Effects of cyclic freezing and thawing on volume changes and permeabilities of soft fine-gained soils. Canadian Geotechnical Journal 1996, 33, 529-537.

4. Chai, L.; Zhang, L.; Lv, X.; Hao, Z.; Liu, S. An investigation into the feasibility of using passive microwave remote sensing to monitor freeze/thaw erosion in China. IEEE Journal of Selected Topics in Applied Earth Observations and Remote Sensing 2014, 1-10.

5. Guo, B.; Jiang, L. Evaluation of freeze-thaw erosion in Qinghai-Tibet Plateu based on multi-source data. Bulletin of Soil and Water Conservation 2017, 37, 12-19.

6. Jing, G. Study on freeze-thaw erosion and its form. Heilongjiang Hydraulic Science and Technology 2003, 33, 
111-112.

7. Wei, X.; Ding, Y.; Li, X. Review and prospect of freeze-thaw-induced erosion research. Research of Soil and Water Conservation 2012, 19, 271-275.

8. Jing, G.; Liu, B.; Rong, J.; Sun, X. Distribution and characteristics of freeze-thaw erosion in Heilongjiang province. Bulletin of Soil and Water Conservation 2016, 36, 320-325.

9. Ministry of Water Resources. Soil erosion control and ecological security in China, Soil erosion data volume; Science Press: 2010.

10. Zhang, J.; Lu, P.; Zhou, Z.; Zhang, W. Melting and shrinkage of cryosphere in Tibet and its impact on ecology and environment. Arid Land Geography 2010, 33, 703-709.

11. Liu, S.; Liu, B.; Tao, H.; Zhang, L. Freeze-thaw erosion status and control measures in China. Soil and Water Conservation in China 2013, 41-44.

12. Wang, X. Observation and exploration of freeze-thaw erosion in Tibetan plateau. Soil and Water Conservation in China 2014, 51-53.

13. Tao, H.; Liu, S.; Fan, J.; W. Soil and water loss division and control measures in Tibet. Soil and Water Conservation in China 1999, 21-23.

14. Dong, R.; Xu, Z.; Yang, Y. Freeze-thaw erosion in Qinghai-Tibet Plateau. Yangtze River 2000, 39-41.

15. Li, D.; Wei, X.; Li, X.; Li, Y. Sensitivity evaluation of freeze-thaw erosion in Gansu province based one RS and GIS. Research of Soil and Water Conservation 2015, 22, 1-6.

16. Li, H.; Liu, S.; Zhong, X.; Zhang, J.; Wang, X. GIS-based sensitivity evaluation on freeze-thaw erosion in Tibet. Soil and Water Conservation in China 2005, 44-46+51.

17. Li, Z.; Zhu, B.; Li, P. Advancement in study on soil erosion and soil and water conservation. Acta Pedologica Sinica 2008, 45, 802-809.

18. Zhang, R.; Wang, X.; Fan, H.; Zhou, L.; Wu, M.; Liu, Y. Study on the regionalization of freeze-thaw zones in China and the erosion characteristics. Science of Soil and Water Conservation 2009, 7, 24-28.

19. Wang, L.; Xiao, Y.; Jiang, L.; Ouyang, Z.. Assessment and analysis of the freeze-thaw erosion sensitivity on the Tibetan Plateau. Journal of Glaciology and Geocryology 2017, 39, 61-69.

20. Fan, H.; Cai, Q. Review of research progress in freeze-thaw erosion. Science of Soil and Water Conservation 2003, 1, 50-55.

21. Wu, W.; Liu, F. Dynamic analysis and distribution characteristics of freeze-thaw erosion in the Three-rivers' headstream region. Journal of Qinghai Normal University(Natural Science Edition) 2010, 26, 57-61.

22. Zhang, J.; Sha, Z.; Wang, J.; Qi, F.; Chen, X.; Song, C. Freezing-thawing erosion in the Qinghai Lake Basin based on remote sensing and GIS. Journal of Glaciology and Geocryology 2012, 34, 375-381.

23. Ouyang, Y.; Shen, W.; Yang, K.; Lin, N. The trend of freeze-thaw erosion in Yarlung Zangbo River Basin in nearly twenty years. Mountain Research 2014, 32, 417-422.

24. Qian, D.; Zhuang, X.; Zhang, B. Types of freeze-thaw erosion and driving force of frigid zone. Soil and Water Conservation in China 2014, 16-17+69.

25. Sun, B.; Li, Z.; Xiao, J.; Zhang, L.; Ma, B.; Li, J.; Cheng, D. Research progress on the effect of freeze-thaw on soil physical and chemical properties and wind and water erosion. Chinese Journal of Applied Ecology 2019, 30, 337-347.

26. Jing, G. Study on types of freeze-thaw erosion and its characteristics. Soil and Water Conservation in China 2003, 21-22+46.

27. Zhang, J.; Liu, S.; Fan, J. Identification and evaluation of freeze-thaw erosion in Sichuan province on the basis of GIS. Mountain Research 2005, 23, 248-253. 
28. Li, C.; Ma, J.; Tang, Z.; Zhou, W. GIS-based evaluation on intensity of freeze-thaw erosion in headwater region of the Three-River-Source area. Soil and Water Conservation in China 2011, 41-43+69.

29. Shi, Z.; Tao, H.; Liu, S.; Liu, B.; Guo, B. Research of freeze-thaw erosion in the Three-River-Source area based on GIS. Transactions of the Chinese Society of Agricultural Engineering 2012, 28, 214-221+300.

30. Lu, Y.; Zhang, T.; Liu, Y.; You, Y.; Feng, C.; Kong, W. Evaluation and spatial distribution characteristics of freeze-thaw erosion intensity in the Yalu Tsangpo River basin on the basis of geographic information system. Geomatics, Natural Hazards and Risk 2019, 10, 1047-1069, doi:10.1080/19475705.2018.1564705.

31. Bing, G.; Yi, Z.; Zhu, J.; Liu, W.; Wang, F.; Wang, L.; Lin, J. An estimation method of soil freeze-thaw erosion in the Qinghai-Tibet Plateau. Natural Hazards 2015, 78, 1843-1857.

32. Chai, L.; Zhang, L.; Hao, Z.; Jiang, L.; Kou, X. A new method to determine the freeze-thaw erosion. In Proceedings of Geoscience \& Remote Sensing Symposium; pp. 747-752.

33. Kong, B.; Yu, H. Estimation model of soil freeze-thaw erosion in Silingco watershed wetland of Northern Tibet. Scientificworldjournal 2013, 2013, 1-7.

34. Zhang, J.; Liu, S.; Yang, S. Classification and Assessment of Freeze- thaw Erosion in Tibet. Acta Geographica Sinica 2006, 911-918.

35. Shuzhen, Z.J.L. The classification and assessment of freeze-thaw erosion in Tibet. Journal of Geographical Sciences 2007, 165-174.

36. Li, Z.; Liu, S.; Zhang, J.; Zhang, L. Survey method of freeze-thaw erosion in China. Science of Soil and Water Conservation 2012, 10, 1-5.

37. Chen, J.; Zhou, L. Monitoring and analysis of freeze-thaw erosion in Dadu River Basin. Technology of Soil and Water Conservation 2013, 14-16.

38. Saaty, T.L. Decision making with the analytic hierarchy process. International Journal of Services Sciences 2008, 1, 83-98.

39. Saaty, T.L. How to make a decision: The analytic hierarchy process. European Journal of Operational Research 1994, 48, 9-26.

40. Bing, G.; Wei, L.; Dong-liang, W.; Lin, J. Spatial and temporal change patterns of freeze-thaw erosion in the three-river source region under the stress of climate warming. Journal of Mountain Science 2017, 14, 1086-1099.

41. Ye, Q.; Li, S.; Zhang, Y.; Shu, X.; Ni, D. Cloud model and application overview. Computer Engineering and Design 2011, 32, 4198-4201.

42. Fu, B.; Li, D.; Wang, M. Review and prospect on research of cloud model. Application Research of Computers 2011, 28, 420-426.

43. Wang, H.; Feng, Y. Improved AHP based on judgment matrix scaled with cloud model. Chinese Journal of Management Science 2005, 13, 32-37.

44. Jia, X.; Xu, J. Cloud model-based seismic risk assessment of road in earthquake region. Journal of Tongji University(Natural Science) 2014, 42, 1352-1358+1458.

45. Zhang, Q.; Zhang, Y.; Zhong, M. A cloud model based approach for multi-hierarchy fuzzy comprehensive evaluation of reservoir-induced seismic risk. Journal of Hydraulic Engineering 2014, 45, 87-95.

46. Song, J.; Han, J.; Zhang, D.; Lin, Y.; Shao, L. Evaluation of security vulnerability severity based on CMAHP. In Proceedings of IEEE International Conference on Computer \& Communications; pp. 1056-1060.

47. Yang, S.; Han, X.; Bo, C.; Bo, L.; Fei, Y. Cloud-model-based method for risk assessment of mountain torrent disasters. Water 2018, 10, 830-850.

48. Sun, Z.; Song, C.; Li, W.; Chen, D. On erosion mechanism and coutrol measures of freezing and thawing. 
Journal of Engineering of Heilongiiang University 1999, 34-35+42.

49. Song, J.; Tang, G.; Wang, C.; Xiao, C. Edge effect analysis on deriving slope from grid DEM. Bulletin of Soil and Water Conservation 2006, 26, 82-85+116.

50. $\mathrm{Xu}, \mathrm{X}$. China annual vegetation index (NDVI) spatial distribution dataset. Data Registration and Publication System for Resource and Environmental Science Data Center, Chinese Academy of Sciences (RESDC)., Ed. 2018; 10.12078/2018060601.

51. Karger, D.N.; Conrad, O.; Böhner, J.; Kawohl, T.; Kreft, H.; Soriaauza, R.W.; Zimmermann, N.E.; Linder, H.P.; Kessler, M. Data from: Climatologies at high resolution for the earth's land surface areas. Dryad digital repository 2017, 4, 170122.

52. Karger, D.N.; Conrad, O.; Böhner, J.; Kawohl, T.; Kreft, H.; Soriaauza, R.W.; Zimmermann, N.E.; Linder, H.P.; Kessler, M. Climatologies at high resolution for the earth's land surface areas. Sci Data 2017, 4, 170122.

53. Zhang, J.; Liu, S. A new way for definiting the freezing- thaw erosion area in Tibet. Geography and Geo-Information Science 2005, 21, 32-34+47.

54. Wang, Z.; Sha, Z.; Ma, Y.; Hu, J.; Zhai, Y.; Ma, H. Intensity and spatial distribution characteristics of soil freeze-thaw erosion in alpine steppe region based on GIS. Journal of Earth Environment 2017, 8, 55-64.

55. Lv, H.; Wang, Y.; Li, D.; Liu, C. The application of backward cloud in qualitative evaluation. Chinese Journal of Computers 2003, 1009-1014.

56. Li, D.; Liu, C.; Gan, W. A new cognitive model: Cloud model; 2009; Vol. 24, pp. 357-375.

57. Li, D.; Liu, C. Study on the universality of the normal cloud model. Strategic Study of CAE 2004, 6, 28-34.

58. Jiang, Y.; Zhang, Q. A fuzzy comprehensive assessment system of dam failure risk based on cloud model. Journal of Computers 2013, 8, 1043-1049, doi:10.4304/jcp.8.4.1043-1049.

59. Li, D. Uncertainty reasoning based on cloud models in controllers. Computers and Mathematics with Applications 1998, 35, 99-123.

60. Li, D.; Di, K.; Li, D.; Shi, X. Mining association rules with linguistic cloud models. In Proceedings of Research \& Development in Knowledge Discovery \& Data Mining, Second Pacific-asia Conference, Pakdd-98, Melbourne, Australia, April.

61. Di, K.; Li, D.; Li, D. Model and their applications in spatial data mining. In Proceedings of the Ninth National Image Graphics Technology Conference, Xi'an, China; p. 6.

62. Liu, C.; Li, D.; Du, Y.; Han, X. Some statistical analysis of the normal cloud model. Information and Control 2005, 34, 236-239+248.

63. Di, K.; Li, D.; Li, D. Cloud theory and its applications in spatial data mining and knowledge discovery. Journal of Image and Graphics 1999, 4, 930-935.

64. Wang, H.; Feng, Y.. On multiple attribute group decision making with linguistic assessment inf ormation based on cloud model. Control and Decision 2005, 20, 679-681+685.

65. Liu, T. Research on uncertain linguistic multi-criteria group decision-making method based on cloud model and its application. Master, Central South University, 2011.

66. Jiang, Y. Study on risk analysis and disaster loss assessment of dam break based on cloud model and GIS/RS. Doctor, Huazhong University of Science and Technology, 2012.

67. Wang, J.; Liu, T. Uncertain linguistic multi-criteria group decision-making approach based on integrated cloud. Control and Decision 2012, 27, 1185-1190.

68. Zhang, J.; Liu, S. Spatial distribution characteristics of freeze-thaw erosion in Tibet. Research of Soil and Water Conservation 2008, 15, 1-6. 